\title{
Dehalogenation Polymerization of 1,1'-Dihaloferrocene with Magnesium as a New Convenient Synthetic Route to Poly(1,1'-ferrocenylene)
}

\author{
Kenichi SANechika, Takakazu Yamamoto,* \\ and Akio YAMAMOTO \\ Research Laboratory of Resources Utilization, Tokyo Institute of Technology, \\ 4259 Nagatsuta, Midori-ku, Yokohama 227, Japan.
}

(Received July 26, 1980)

\begin{abstract}
Dibromoferrocene and 1,1'-diiodoferrocene are readily converted into poly $\left(1,1^{\prime}\right.$-ferrocenylene) in a $45-77 \%$ yield by dehalogenation polymerization with magnesium, $n\left(\mathrm{XC}_{5} \mathrm{H}_{4} \mathrm{FeC}_{5} \mathrm{H}_{4} \mathrm{X}\right)+n \mathrm{Mg} \rightarrow\left(\mathrm{C}_{5} \mathrm{H}_{4} \mathrm{FeC}_{5} \mathrm{H}_{4} \gamma_{n}+n \mathrm{MgX}_{2}\right.$. The polymer obtained was fractionated into four parts by solubilities in organic solvents: Fraction I (soluble in hexane, 23-29 wt $\%$ ), Fraction II (soluble in $\mathrm{C}_{6} \mathrm{H}_{6}$ at room temperature but nonsoluble in hexane, $6-11 \mathrm{wt} \%$ ), Fraction III (soluble in $\mathrm{C}_{6} \mathrm{H}_{6}$ at $80^{\circ} \mathrm{C}$ but nonsoluble at room temperature, 6-12 $\mathrm{wt}^{\%} \%$ ), and Fraction IV (insoluble in $\mathrm{C}_{6} \mathrm{H}_{6}$ at $80^{\circ} \mathrm{C}, 47-62 \mathrm{wt} \%$ ). Infrared (IR) and nuclear magnetic resonance (NMR) spectra of Fractions I-IV indicate that they are constituted of regularly recurring 1,1'ferrocenylene units. The number-average molecular weights of Fractions I and II are about 900 and 1500 respectively as determined by vapor pressure osmometry (VPO), whereas that of Fraction IV was calculated as about 4600 from analytical data, assuming that both polymer ends have halogen. The polymers have high thermal stabilities and the thermal stabilities are enhanced by preparing the polymer in the presence of a nickel compound, $\mathrm{NiCl}_{2}\left(2,2^{\prime}\right.$-bipyridine $)$. The $\mathrm{X}$-ray diffraction pattern of the powdery polymer shows fairly sharp peaks, indicating the presence of micro crystals. Doping of Fraction IV with acceptors such as iodine and 7,7,8,8-tetracyano-p-quinodimethane (TCNQ) afforded semi-conducting materials having electric condutivities of $10^{-2}-10^{-4} \mathrm{~S} \mathrm{~cm}^{-1}$ at room temperature.

KEY WORDS Poly $\left(1,1^{\prime}\right.$-ferrocenylene) / Polycondensation / Thermostable
\end{abstract}

Polymer / Semi-Conducting Polymer /

The polymer having recurring $1,1^{\prime}$ 'ferrocenylene units has attracted polymer and organometallic chemists for many years. ${ }^{1-4}$ Interest has recently been enhanced especially in connection with the mixed-valency character of the polymeric ferrocenes. ${ }^{2}$ Although several methods, including oxidative coupling reactions of 1,1'-dilithioferrocenes ${ }^{3}$ and Ullmann-type coupling of $1,1^{\prime}$-dihaloferrocenes, ${ }^{4}$ have been developed for the prepara- tion of poly $\left(1,1^{\prime}\right.$-ferrocenylene), some of the methods require starting materials difficult to prepare and most of the methods give polymers only in low yields.

We now report a new convenient route to poly $\left(1,1^{\prime}\right.$-ferrocenylene) by dehalogenation of $1,1^{\prime}$ dihaloferrocene, which is easily prepared from ferrocene,${ }^{5}$ with magnesium:

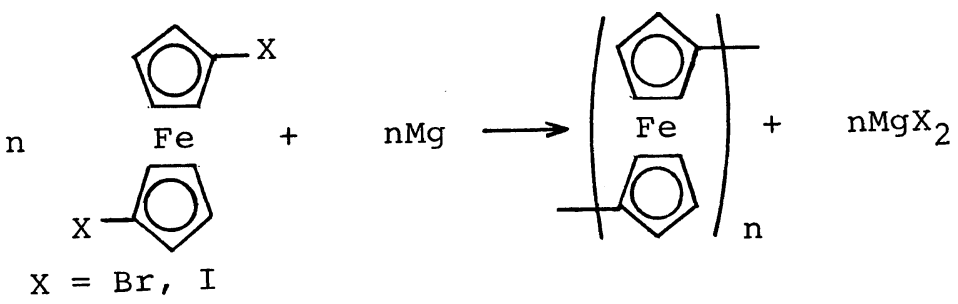


The reaction resembles the dehalogenation polymerization of $1,1^{\prime}$-dihaloferrocene with $\mathrm{Cu}$, using the Ullmann-type coupling reaction. ${ }^{4}$ However, the present method can be carried out under much milder reaction conditions and affords the polymer with a higher molecular weight in high yield.

\section{EXPERIMENTAL}

\section{Material}

$1,1^{\prime}$-Dihaloferrocenes were prepared and purified according to a method developed by Kovar and his coworkers. ${ }^{5}$ 1',6'-Dibromobiferrocenyl $\left(\mathrm{BrC}_{5} \mathrm{H}_{4} \mathrm{FeC}_{5} \mathrm{H}_{4}\right)_{2}$ was obtained as a by-product in the preparation of $1,1^{\prime}$-dibromoferrocene. ${ }^{5}$ Tetrahydrofuran used in the polymerization was dried over $\mathrm{Na}$ wire, distilled under nitrogen, and stored under nitrogen. Dichloro(2,2'-bipyridine)nickel was prepared according to the literature. ${ }^{6}$ Benzonitrile and acetonitrile used in the doping of 7,7,8,8-tetracyano-p-quinodimethane (TCNQ) were dried over $\mathrm{CaH}_{2}$, and distilled under nitrogen.

\section{Preparation of Poly (1,1'-ferrocenylene)}

Run 1 (cf. Table I). When a dry THF $(10 \mathrm{ml})$ solution of a mixture of $1.0 \mathrm{~g}(2.9 \mathrm{mmol})$ of $1,1^{\prime}$ dibromoferrocene and $0.55 \mathrm{~g}(2.9 \mathrm{mmol})$ of $1,2-$ dibromoethane, an activating agent of magnesium in the preparation of Grignard reagents of haloferrocenes, ${ }^{7}$ was added dropwise to $0.14 \mathrm{~g}(0.58 \mathrm{mmol})$ of magnesium under an atmosphere of nitrogen at room temperature, a smooth polymerization started to give an orange precipitate. After stirring for 1 day, the reaction mixture was poured into $50 \mathrm{ml}$ of dé-jxygenated $1 \mathrm{~N} \mathrm{HCl}$-acidic water containing $\mathrm{SnCl}_{2}\left(1 \mathrm{~mol} \mathrm{1^{-1 } )}\right.$ to remove the magnesium. compounds. The orange precipitate was washed thoroughly with methyl alcohol, and dried in vacuo to give $0.44 \mathrm{~g}$ of orange crude poly $\left(1,1^{\prime}\right.$ ferrocenylene). The yield, based on the amount of carbon taken into polymer, was calculated from the weight and carbon content of the polymer to be $77 \%$. The crude polymer was fractionated into four parts by extracting with organic solvents. Fraction I $(0.10 \mathrm{~g})$ was obtained by extracting the crude polymer by hot hexane with a Soxhlet extractor. Fractions II and III were obtained by extracting with hot benzene. On cooling the benzene solution to room temperature, Fraction III (0.03) was deposited, whereas Fraction II remained in the solution. Drying up the solution gave $0.04 \mathrm{~g}$ of Fraction II. The remaining benzene-unextractable polymer was dried in vacuum to yield $0.27 \mathrm{~g}$ of Fraction IV. Preparation of the other polymers listed in Table I was carried out in a similar manner.

\section{Doping of the polymer with Acceptors}

Doping with $\mathrm{I}_{2}$. A vessel containing $126 \mathrm{mg}$ of the powdery Fraction IV was connected to a vacuum line and evacuated. The polymer was then exposed to $I_{2}$ vapor for 1 day at room temperature. The composition of the iodine adduct of the polymer was computed as $\left(\mathrm{C}_{10} \mathrm{H}_{8} \mathrm{Fe} 0.96 \mathrm{I}_{n}\right.$ from an increase $(81 \mathrm{mg})$ in the weight of the polymer. Elemental analysis of the polymer doped with iodine was consistent with the computed composition.

Doping with $T C N Q$. A mixture of Fraction IV (123 mg) and TCNQ (272 mg) was stirred in dry benzonitrile under an atmosphere of nitrogen for $13 \mathrm{~h}$ at room temperature. Excess TCNQ was removed by washing the TCNQ adduct with deoxygenated, dry acetonitrile. Elemental analysis indicated the formation of a material having a composition of $\left(\mathrm{C}_{10} \mathrm{H}_{8} \mathrm{Fe} 0.64 \mathrm{TCNQ}\right)_{n}$.

\section{Instrumental Analyses and Elemental Analysis}

Infrared (IR) spectra were recorded on a Hitachi Model 295 infrared spectrophotometer. Thermogravimetric analysis was performed using a Shimadzu DT-30 thermal analyzer under $\mathrm{N}_{2}$. The number-average molecular weight was determined with a Hitachi-Perkin-Elmer Model 115 vapor pressure osmometer. The electric conductivity of the solid polymer with and without doping was measured by a Takeda Riken TR-8651 electrometer after molding the polymer into a disk $(\phi=13 \mathrm{~mm}$, $d=1 \sim 2 \mathrm{~mm})$ under a pressure of $500 \mathrm{~kg} \mathrm{~cm}^{-2}$ at room temperature for $5 \mathrm{~min}$. Magnetic susceptibility was measured with the aid of a Shimadzu MB-100 magnetic balance. X-Ray diffraction spectra were obtained with a Phillips PW-1051 X-Ray Diffractometer. Microanalysis of $\mathrm{C}, \mathrm{H}$, and $\mathrm{N}$ was performed by Mr. T. Saito at our laboratory with a Yanagimoto CHN Autocorder Type MT2.

\section{RESULTS AND DISCUSSION}

\section{Preparation of Poly (1,1'-ferrocenylene)}

1,1'-Dibromoferrocene and 1,1'-diiodoferrocene 
A New Synthesis of Poly(1,1'-ferrocenylene)

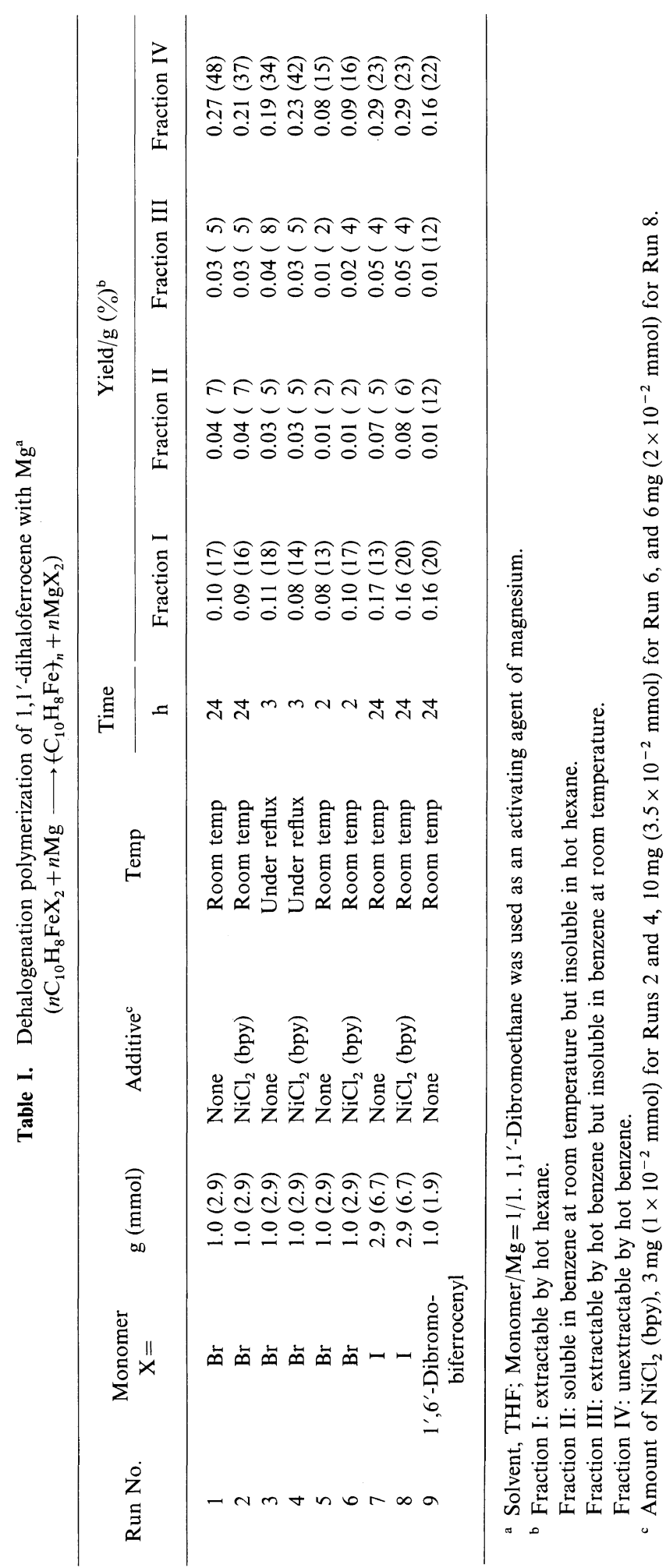


are readily converted into poly(1,1'-ferrocenylene) by a dehalogenation reaction with magnesium, according to eq 1 . Polycondensation most probably proceeds stepwisely through coupling reactions between the ferrocenyl halides and Grignard reagents formed by the reaction with $\mathrm{Mg}$, Table I

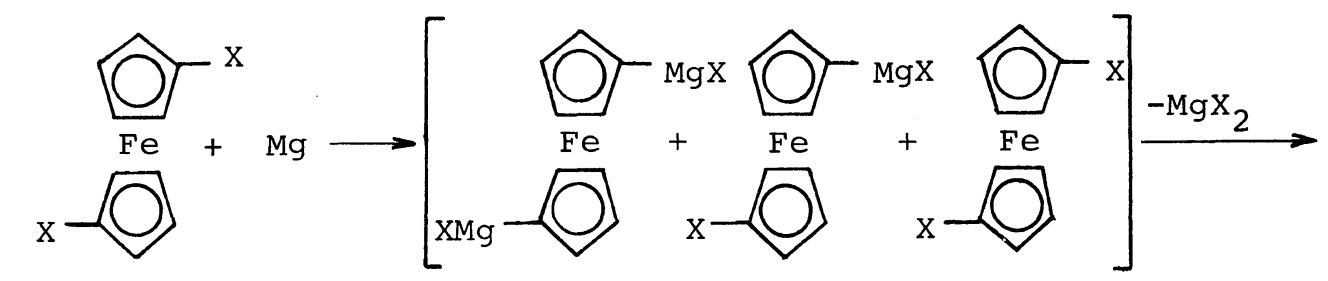

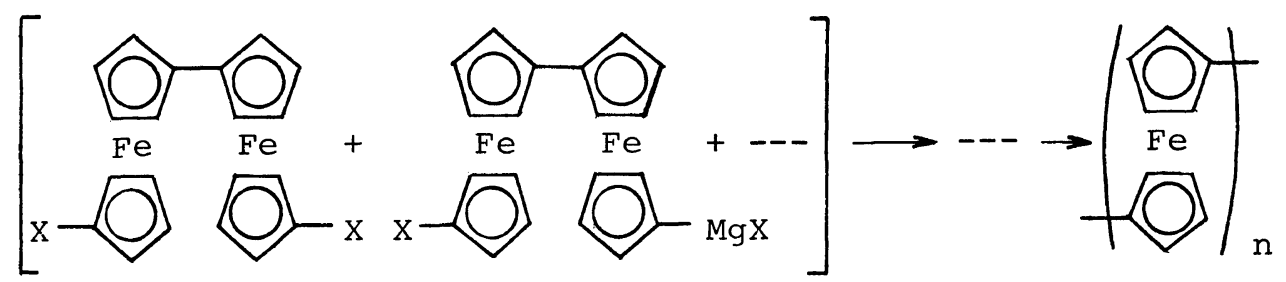

shows the results of the polymerization. 1,1'Dibromoferrocene gives a higher yield than the 1,1'diiodoanalog and the proportion of the benzeneunextractable fraction, Fraction IV, is somewhat larger when 1,1'-dibromoferrocene is employed as the monomer. The proportion of Fraction IV decreased when monomers without sufficient purifi- cation was employed. Use of $1^{\prime}, 6^{\prime}$-dibromobiferrocenyl $\left(\mathrm{BrC}_{5} \mathrm{H}_{4} \mathrm{FeC}_{5} \mathrm{H}_{4}\right)_{2}$ as the monomer gave a similar result (No. 9 in Table I) thus supporting the intervention of oligomers such as $1^{\prime}, 6^{\prime}$-dibromobiferrocenyl in the polymerization of $1,1^{\prime}$-dihaloferrocene. The Addition of dichloro(2,2'-bi-

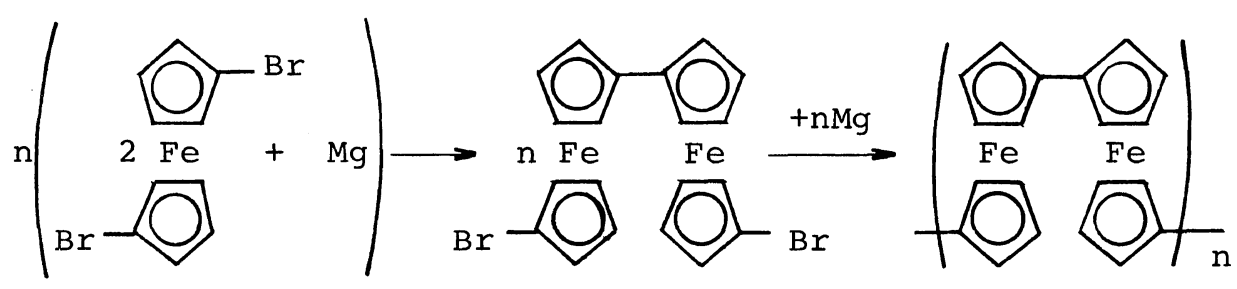

$1^{\prime}, 6^{\prime}$-dibromobiferrocenyl

pyridine)nickel, $\mathrm{NiCl}_{2}$ (bpy), (Runs 2, 4, 6, and 8) scarcely affects the polymer yield and the proportion of Fraction IV, although the polymers prepared in the presence of $\mathrm{NiCl}_{2}$ (bpy) have higher thermal stabilities than those prepared without $\mathrm{NiCl}_{2}$ (bpy) (vide infra). In the case of the dehalogenation polymerization of ordinary dihaloaromatic compounds with $\mathrm{Mg}$, the addition of transition-metal catalysts such as $\mathrm{NiCl}_{2}$ (bpy) is indispensable, ${ }^{8}$ unless the carbon-halogen bond in the dihaloaromatic compound is highly reactive as observed in the case of allylic halides. ${ }^{8,9}$ The occurrence of the facile polymerization of $1,1^{\prime}$ dihaloferrocene in the absence of a transition-metal catalyst indicates that the $\mathrm{C}-\mathrm{X}$ and $\mathrm{C}-\mathrm{MgX}$ bonds attached to the cyclopentadienyl ring of ferrocene are highly reactive to coupling with each other spontaneously.

Characterization and Properties of $\operatorname{Poly}\left(1,1^{\prime}-\right.$ ferrocenylene) IR and Nuclear Magnetic Resonance (NMR) Spectra

The IR spectra of Fractions I-IV are essentially the same as that of poly $\left(1,1^{\prime}\right.$-ferrocenylene $)$ pre- 
pared by the other methods, ${ }^{1,3,4}$ showing absorption bands at $3080 \mathrm{~m}, 1415 \mathrm{~m}, 1380 \mathrm{w}, 1350 \mathrm{w}, 1110 \mathrm{~s}$, $1050 \mathrm{~m}, 1030 \mathrm{~s}, 995 \mathrm{~s}, 795 \mathrm{~s}, 675 \mathrm{~m}, 605 \mathrm{~m}$, and $480 \mathrm{vs}$ $\mathrm{cm}^{-1}$. The simple absorption pattern in the region of out of plane $\left(1200-800 \mathrm{~cm}^{-1}\right)$ and ringdistortion $\left(880-400 \mathrm{~cm}^{-1}\right)$ vibrations ${ }^{10}$ indicates that the polymer has a regularly-repeated structure. The IR spectrum shows no band characteristic of 1,1'-biferrocenylene, $\left(\mathrm{C}_{5} \mathrm{H}_{4} \mathrm{FeC}_{5} \mathrm{H}_{4}\right)_{2},{ }^{11}$ which is sometimes produced by the cyclization of $1,1^{\prime}$ disubstituted ferrocenes. ${ }^{1 d, 3,12}$ In addition to these absorption bands characteristic of the recurring ferrocenylene unit, the IR spectra of Fractions I, II, and III show two very weak absorption bands at 870 $\mathrm{cm}^{-1}$ and about $2900 \mathrm{~cm}^{-1}$, which are assignable to $v(\mathrm{C}-\mathrm{X})$ and $v(\mathrm{C}-\mathrm{H})$ of $\mathrm{CH}_{2}$ units. The band at 870 $\mathrm{cm}^{-1}$, considered due to the terminal haloferrocenyl unit, ${ }^{10}$ becomes weaker with a decrease in the solubility of the polymer. The appearance of the band at about $2900 \mathrm{~cm}^{-1}$ suggests that Fractions I, II, and III each contain a small amount of aliphatic units which probably originated from 1,2-dibromoethane. The absorption bands at $870 \mathrm{~cm}^{-1}$ and $2900 \mathrm{~cm}^{-1}$ were not observable in the IR spectrum of Fraction IV. The NMR spectra of Fractions I and II in benzene- $d_{6}$ are almost the same as those reported for poly $\left(1,1^{\prime}\right.$-ferrocenylene) prepared by polycondensation between dilithioferrocene and $1,1^{\prime}$-diiodoferrocene, ${ }^{3}$ showing a broad strogn signal in the region from $\delta 3.8$ to $4.4 \mathrm{ppm}$ with a shoulder at about $\delta 3.9 \mathrm{ppm}$, presumably due to protons in the terminal rings. A weak signal is also observed at $\delta 2.0 \mathrm{ppm}$, and is assignable to $\mathrm{CH}_{2}$ protons adjacent to the cyclopentadienyl ring of ferrocenylene.

\section{X-Ray Diffraction}

The X-ray diffraction spectrum of poly $\left(1,1^{\prime}\right.$ ferrocenylene) shows two fairly sharp peaks at $16.5^{\circ}$ (half width, $c a .0 .5^{\circ}$ ) and $20.2^{\circ}$ (half width, $c a .0 .4^{\circ}$ ). The positions and sharpness of the two peaks are virtually independent of the kind of the monomer employed, the presence or the absence of $\mathrm{NiCl}_{2}$ (bpy) in the preparation of the polymer, and the solubility of the sample. The preparation of crystalline poly $\left(1,1^{\prime}\right.$-ferrocenylene) has no precedent.

\section{Molecular Weight}

The number-average molecular weights of Fractions I and II obtained from 1,1'-dibromofer- rocene (Run 1) were 860 and 1470, respectively, as determined by vapor pressure osmometry. The molecular weight of each fraction showed little variance with the preparative methods, suggesting that the molecular weight is the dominant factor for determining the solubility of the polymer. The molecular weights of Fractions III and IV could not be measured due to the insolubility of the polymers in usual organic and inorganic solvents. However, if one assumes that both polymer ends have halogen, the number-average degree of polymerization $(\overline{D P})$ of Fraction IV obtained in Run 1 is computed from the analytical data $(\mathrm{C}, 61.5 \% ; \mathrm{H}$, $4.2 \% ; \mathrm{Br}, 4.1 \%$ ) as 20 , and corresponds to a molecular weight of 3800 . The calculated content of $\mathrm{C}, \mathrm{H}$, and $\mathrm{Br}$ in $\mathrm{Br}\left(\mathrm{C}_{10} \mathrm{H}_{8} \mathrm{Fe}\right)_{20} \mathrm{Br}$ is $62.5 \%, 4.2 \%$, and $4.1 \%$, respectively. The $\overline{D P}$ value of Fraction IV obtained in Run 2 is computed in a way similar as 24, (Anal. Calcd: for $\mathrm{Br}\left(\mathrm{C}_{10} \mathrm{H}_{8} \mathrm{Fe}\right)_{24}: \mathrm{C}, 62.9 \% ; \mathrm{H}$, $4.2 \%, \mathrm{Br}, 3.5 \%$. Found: C, $62.5 \%$; $\mathrm{H}, 4.3 \% ; \mathrm{Br}$, $3.3 \%)$.

\section{Melting Point and Thermal Stabilities}

Fractions I and II melt at $130-140^{\circ} \mathrm{C}$ and $200-$ $210^{\circ} \mathrm{C}$, respectively, whereas Fractions III and IV do not melt up to $360^{\circ} \mathrm{C}$. Figure 1 shows the results of the thermogravimetric analyses (TGA) of Fractions IV, prepared in Runs 1 and 2. The TGA curves show that Fraction IV prepared in the presence of $\mathrm{NiCl}_{2}$ (bpy) has a very high thermal stability with relative residual weight of $80 \%$ at about $500^{\circ} \mathrm{C}$ and of $70 \%$ at $900^{\circ} \mathrm{C}$. Although there is no significant difference in the $\overline{D P}$ values of the polymers prepared in Run 1 and Run 2, Fraction IV

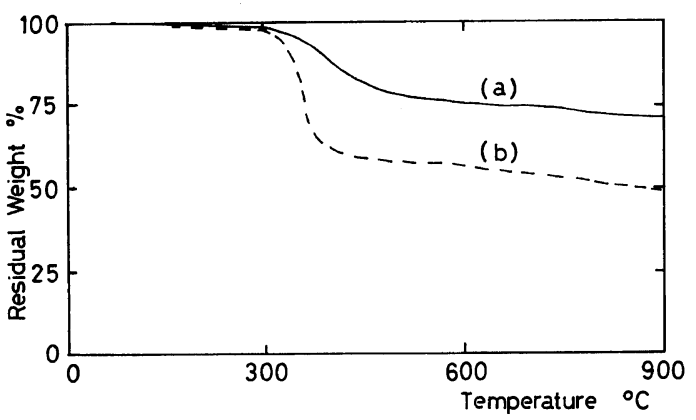

Figure 1. Thermogravimetric analyses of (a) poly $\left(1,1^{\prime}\right.$ ferrocenylene) prepared in the presence of $\mathrm{NiCl}_{2}$ (bpy) (Run 1, Fraction IV) and (b) poly $\left(1,1^{\prime}\right.$-ferrocenylene) prepared in the absence of $\mathrm{NiCl}_{2}$ (bpy) (Run 2, Fraction IV). 
Table II. Magnetic susceptibility $\chi$ and electric conductivity of Fractions I-IV and Fraction IV doped with acceptors

\begin{tabular}{|c|c|c|c|c|}
\hline \multirow{2}{*}{ Sample } & $\chi$ & Electric conductivity ${ }^{a}$ & Temp & Activation energy, $\Delta E_{\mathrm{a}}$ \\
\hline & $\mathrm{cm}^{3} \mathrm{~g}^{-1}$ & $\mathrm{~S} \mathrm{~cm}^{-1}$ & K & $\mathrm{kcal} \mathrm{mol}^{-1}$ \\
\hline Fraction I & $-3.6 \times 10^{-6}$ & $4 \times 10^{-11}$ & 292 & \\
\hline Fraction II & $-5.0 \times 10^{-6}$ & $4 \times 10^{-11}$ & 292 & \\
\hline Fraction III & $6.0 \times 10^{-6}$ & - & 292 & \\
\hline Fraction IV & $1.7 \times 10^{-5}$ & $8 \times 10^{-10}$ & 292 & \\
\hline Fraction IV + Iodine ${ }^{\mathrm{b}}$ & $4.8 \times 10^{-5}$ & $\begin{array}{l}1.3 \times 10^{-4} \\
2.6 \times 10^{-5} \\
8.7 \times 10^{-6} \\
2.0 \times 10^{-6}\end{array}$ & $\begin{array}{l}292 \\
248 \\
223 \\
197\end{array}$ & \} 5.0 \\
\hline Fraction IV + TCNQ & $8.0 \times 10^{-5}$ & $\begin{array}{l}4.1 \times 10^{-2} \\
3.1 \times 10^{-2} \\
1.2 \times 10^{-2} \\
6.9 \times 10^{-3}\end{array}$ & $\begin{array}{l}295 \\
271 \\
220 \\
195\end{array}$ & $\{1.7$ \\
\hline
\end{tabular}

a Measured by a four-points method.

b Fraction IV+Iodine $=\left(\mathrm{C}_{10} \mathrm{H}_{8} \mathrm{Fe} 0.96 \mathrm{I}\right)_{n}$.

c Fraction IV $+\mathrm{TCNQ}=\left(\mathrm{C}_{10} \mathrm{H}_{8} \mathrm{Fe} 0.64 \mathrm{TCNQ}\right)_{n}$.

prepared in the absence of $\mathrm{NiCl}_{2}$ (bpy) has less thermal stability with a relative residual weight of $60 \%$ at $500^{\circ} \mathrm{C}$ and $50 \%$ at $900^{\circ} \mathrm{C}$. The lower thermal stability of the polymer prepared in the absence of $\mathrm{NiCl}_{2}$ (bpy) may be due to generation of certain radicals in the dehalogenation polymerization with $\mathrm{Mg}$. The generation of radicals may bring about certain irreguralities, such as branching of the polymer, although the IR and X-ray diffraction analyses give no evidence of such irreguralities. On the other hand, the polymer prepared in the presence of $\mathrm{NiCl}_{2}$ (bpy) may not have these irreguralities, since nickel compounds are known to catalyze coupling reactions between organic halides and Grignard reagents with very high selectivities not attainable by radical-type reactions. ${ }^{8,13}$

\section{Magnetic Susceptibility and Electric Conductivity}

The magnetic susceptibility and electric conductivity of Fractions I-IV obtained in Run 1 are given in Table II. It is seen that Fractions I and II are diamagnetic, whereas Fractions III and IV have paramagnetism.

This paramagnetism may arise from the fer- ricinium species, $-\mathrm{C}_{5} \mathrm{H}_{4} \mathrm{Fe}(\mathrm{III}){ }^{+} \mathrm{C}_{5} \mathrm{H}_{4}-$, formed by the partial oxidation of the ferrocenylene unit during the work-up of the polymers, and if this is the case, an increase in the paramagnetic character of the polymers with an increase in the molecular weights indicates that the ferricinium species has higher stability when formed in poly $\left(1,1^{\prime}\right.$ ferrocenylene) having a higher molecular weight. It is known that ferrocene has a high stability in air but can be oxidized by air to give the ferricinium cation under acidic conditions. ${ }^{1 \mathrm{~b}}$ The electric conductivities of Fractions I, II, and IV indicate that the polymers are essentially insulators, although a small increase in the electric conductivity with an increase in molecular weight is observed.

On doping the polymer with acceptors, such as iodine and TCNQ, the electric conductivity drastically increases by a factor of $10^{6}-10^{8}$, to give semiconducting materials. The material with a composition of $\left(\mathrm{C}_{10} \mathrm{H}_{8} \mathrm{Fe} 0.96 \mathrm{I}\right)_{n}$ shows an electric conductivity of $1.3 \times 10^{-4} \mathrm{~S} \mathrm{~cm}^{-1}$ at $292 \mathrm{~K}$ and the activation energy for the electric conduction is computed as $5.0 \mathrm{kcal} \mathrm{mol}^{-1}$ from the Arrhenius plot of the conductivity. Doping with a stronger 
acceptor, TCNQ, affords a material having a higher electric conductivity.

It was previously reported that the electric conductivity of poly(1,1'-ferrocenylene) prepared by a radical coupling reaction also increased on doping with iodine and TCNQ, ${ }^{2 a, 2 c}$ but the materials obtained by doping of our poly(1,1'ferrocenylene) have much higher electric conductivities (by a factor of $10^{3}-10^{4}$ ) than those previously reported. Since it is known that the electric conductivity of a polymer increases with an increase in the crystallinity of the polymer ${ }^{14}$ the large difference in the electric conductivity may be attributed to the difference in the crystallinity between the poly $\left(1,1^{\prime}\right.$-ferrocenylene)s prepared by the present method and the radical coupling reaction. The polymer prepared by the radical coupling reaction contains methylene, methyl, and aliphatic ether units in the polymer chain as was proved by the IR spectrum of the polymer. ${ }^{1 \mathrm{~h}}$ Thus, formation of micro crystals may have been hindered, whereas the IR spectrum of Fraction IV shows virtually no peak other than those attributable to the recurring $1,1^{\prime}$-ferrocenylene units. The $\mathrm{X}$-ray diffraction pattern of the powdery Fraction IV indicates that it contains micro crystals.

The increase in the electric conductivity on doping with acceptors is attributable to partial oxidation of the polymer to give a mixed valence poly $\left(1,1^{\prime}\right.$-ferrocenylene $){ }^{2}$ The increase in the magnetic susceptibility on doping is consistent with this view.

\section{REFERENCES}

1. (a) E. W. Neuse and H. Rosenberg, Rev. Macromol. Chem., 5, 1 (1970) and references therein; (b) E. W. Neuse, Adv. Macromol. Chem., 1, 1 (1968); (c) E. W. Neuse and R. K. Crossland, J. Organomet. Chem., 7, 344 (1967); (d) T. Izumi and A. Kasahara, Bull. Chem. Soc. Jpn., 48, 1955 (1975); (e) I. J. Spilners and J. P. Pellegrini Jr., J. Org. Chem., 30, 3800 (1965); (f)
H. Watanabe, I. Motoyama, and K. Hata, Bull. Chem. Soc. Jpn., 39, 790 (1966); (g) N. Bilow, A. L. Landis, and H. Rosenberg, J. Polym. Sci., A-1, 7, 2719 (1969); (h) H. Rosenberg and E. W. Neuse, $J$. Organomet. Chem., 6, 76 (1966).

2. (a) C. U. Pittman Jr., Y. Sasaki, and T. K. Mukherjee, Chem. Lett., 383 (1975); (b) G. M. Brown, T. J. Meyer, D. O. Cowan, C. LeVanda, F. Kaufman, P. V. Poling, and M. D. Rausch, Inorg. Chem., 14, 506 (1975); (c) D. O. Cowan, J. Park, C. U. Pittman Jr., Y. Sasaki, T. K. Mukherjee, and N. A. Diamond, J. Am. Chem. Soc., 94, 5110 (1972).

3. (a) E. W. Neuse and L. Bednarik, Transition Met. Chem., 4, 87, 104 (1979), (b) E. W. Neuse and L. Bednarik, Macromolecules, 12, 187 (1979).

4. (a) P. V. Roling and M. D. Rausch, J. Org. Chem., 37, 729 (1972); (b) P. V. Roling and M: D. Rausch, $J$. Organomet. Chem., 141, 195 (1977); (c) M. D. Rausch, J. Org. Chem., 26, 1802 (1961).

5. R. F. Kovar, M. D. Rausch, and H. Rosenberg, Organomet. Chem. Synth., 1, 173 (1970/1971).

6. (a) J. A. Broomhead and F. P. Dwyer, Aust. J. Chem., 14, 250 (1961); (b) T. Yamamoto, A. Yamamoto, and S. Ikeda, J. Am. Chem. Soc., 93, 3350 (1971).

7. H. Shechter and J. F. Helling, J. Org. Chem., 26, 1034 (1961).

8. (a) T. Yamamoto and A. Yamamoto, Chem. Lett., 353 (1977); (b) T. Yamamoto, Y. Hayashi, and A. Yamamoto, Bull. Chem. Soc. Jpn., 51, 2091 (1978); (c) T. Yamamoto, K. Sanechika, and A. Yamamoto, J. Polym. Sci., Polym. Lett. Ed., 17, 181 (1979); 18, 9 (1980).

9. M. S. Kharasch and O. Reinmuth, "Grignard Reactions of Nonmetallic Substances," Prentice-Hall Inc., New York, N.Y., 1954.

10. J. N. Willis, Jr., M. T. Ryan, F. L. Hedberg, and H. Rosenberg, Spectrochim. Acta, A, 24, 1561 (1968).

11. N. H. Morrison, Jr. and D. N. Hendrickson, Inorg. Chem., 14, 2331 (1975).

12. F. L. Hedberg and H. Rosenberg, J. Am. Chem. Soc., 91, 1258 (1969).

13. K. Tamao, K. Sumitani, Y. Kiso, M. Zembayashi, A. Fujioka, K. Kodama, I. Nakajima, A. Minato, and M. Kumada, Bull. Chem. Soc. Jpn., 49, 1958 (1976) and references therein.

14. F. Gutmann and L. E. Lyons, "Organic Semiconductors," Wiley, New York, 1967. 